\title{
Redox electrode materials for supercapatteries
}

Linpo $\mathrm{Yu}^{\mathrm{a}}$, George Z. Chen ${ }^{\mathrm{a}, \mathrm{b}, *}$

${ }^{a}$ Department of Chemical and Environmental Engineering, and Centre for Sustainable Energy

Technologies, Faculty of Science and Engineering, University of Nottingham Ningbo China, Ningbo 315100, China

${ }^{\mathrm{b}}$ Department of Chemical and Environmental Engineering, Faculty of Engineering, University of Nottingham, Nottingham NG7 2RD, UK

*E-mail: george.chen@ nottingham.ac.uk

\begin{abstract}
Redox electrode materials, including transition metal oxides and electronically conducting polymers, are capable of faradaic charge transfer reactions, and play important roles in most electrochemical energy storage devices, such as supercapacitor, battery and supercapattery. Batteries are often based on redox materials with low power capability and safety concerns in some cases. Supercapacitors, particularly those based on redox inactive materials, e.g. activated carbon, can offer high power output, but have relatively low energy capacity. Combining the merits of supercapacitor and battery into a hybrid, the supercapattery can possess energy as much as the battery and output a power almost as high as the supercapacitor. Redox electrode materials are essential in the supercapattery design. However, it is hard to utilise these materials easily because of their intrinsic characteristics, such as the low conductivity of metal oxides and the poor mechanical strength of conducting polymers. This article offers a brief introduction of redox electrode materials, the basics of supercapattery and its relationship with pseudocapacitors, and reviews selectively some recent progresses in the relevant research and development.
\end{abstract}

Key words: Redox materials; Pseudocapacitance; Capacitive Faradaic process; Non-capacitive Faradaic process; Supercapattery; Supercapacitor 


\section{Introduction}

The foreseeable exhaustion of fossil reserves, which is accompanied by the increasing negative environmental impact of $\mathrm{CO}_{2}$ emission, is calling for development of technologies that can enable either or both of more efficient energy consumption and more reliable utilisation of renewable sources of energy. There are various existing technologies that can improve the efficiency of energy consumption, such as kinetic energy recovery systems [1] and electrical load shifting [2]. In these technologies, the energy storage system must be able to charge and discharge quickly. Because of the recent political and economic emphasises on the optimisation of energy supply structures, alternative energy technologies are being rapidly developed, particularly through solar, wind and wave generation. However, the energy harvested from these renewable sources must be stored and supplied efficiently at affordable costs in competition with traditional non-renewable options [3]. One of the solutions has been recognized to be electrochemical energy storage devices such as supercapacitor and battery which are able to store charges in a fast and efficient way and hence help harvest and convert renewable energy to a usable form. One type of supercapacitors is the electric double layer capacitor (EDLC) which can, for example, output a very high specific power of $90 \mathrm{~kW}$ $\mathrm{kg}^{-1}$, but the specific energy is in the range of $2 \sim 8 \mathrm{Wh} \mathrm{kg}^{-1}$ [3] which can be improved by using the so called pseudocapacitance as explained below. On the other hand, lithium (Li) ion batteries have the highest specific energy (up to $170 \mathrm{Wh} \mathrm{kg}^{-1}$ ) amongst available commercial rechargeable batteries, but prohibitively lower specific power (about $0.2 \sim 1.8 \mathrm{~kW} \mathrm{~kg}^{-1}$ ) than supercapacitors.

As a compromise between EDLC and rechargeable battery, a special type of redox active materials, such as electronically conducting polymers and transition metal oxides, have been developed and investigated to utilise their pseudocapacitance. Such materials can technically perform in the same way as the EDLC materials for charge storage, but the storage mechanism is Faradaic in nature, and hence the term pseudocapacitance. More specifically, pseudocapacitance corresponds to rectangular cyclic voltammograms (CVs) and linear plots of galvanostatic charging and discharging (GCDs). Note that the electrode materials in batteries also rely on the Faradaic 
charge storage mechanism which is however non-capacitive, corresponding to peak-shaped CV and non-linear GCD [3-5].

Recently, supercapattery (= supercapacitor + battery) [3-5] has been proposed as a new term to represent a wide range of devices that take advantages of both capacitive and faradaic charge storage mechanisms at either the electrode material level or, more often, the device level. Note that capacitive charge storage can be non-faradaic (e.g. EDLC) or faradaic (pseudocapacitive), or both, whilst faradaic charge storage can be capacitive (pseudocapacitive) or non-capacitive (battery-like). As a result, supercapattery includes very many combinations but has the same aim that is to achieve the high power capability of supercapacitors and the large storage capacity of batteries [6].

At the materials level, all highly porous structures and nanoparticulates of redox active materials, either capacitive or non-capacitive, can in principle offer both the EDL and faradaic charge storage mechanisms, and hence can be used to build supercapattery. In addition, pseudocapacitive materials represent a special case of supercapattery electrode materials because they are both faradaic and capacitive in nature. Note again that battery electrode materials are faradaic but non-capacitive in nature. It is acknowledged that the term pseudocapacitor has been used in the literature to describe a device consisting of two electrodes of the same (symmetrical) or different (asymmetrical) pseudocapacitive materials. In the context of this article, pseudocapacitor is considered as a special case of supercapattery.

For devices, it is more desirable for a supercapattery to combine a highly polarisable capacitorlike electrode (i.e. it has a wide potential window) and a battery-like electrode into one device. In such a hybrid, the capacitor-like electrode provides the EDLC or pseudocapacitance or both, and the battery-like electrode contributes, via redox or Faradaic reactions, either pseudocapacitance or noncapacitive charge storage. A supercapattery with two identical or different pseudocapacitive electrodes is the same as a pseudocapacitor. The theoretical calculation of the energy capacity of a hypothetical supercapattery consisting of a Li metal negative electrode (negatrode [6,7]) and a 400 $\mathrm{F} \mathrm{g}^{-1}$ supercapacitor positive electrode (positrode) promises a higher energy capacity than the Li ion 
battery [5]. Because the specific charge capacity of $\mathrm{Li}$ is much larger than that of the supercapacitor electrode, the Li mass is negligible in the supercapattery. The theoretical specific energy for discharging the cell from $3.5 \mathrm{~V}$ to $1.0 \mathrm{~V}$ would then be $400 \times\left(3.5^{2}-1.0^{2}\right) /(2 \times 3.6)=625 \mathrm{Wh} \mathrm{kg}^{-1}$.

Supercapattery is also expected to have high power capability when the capacitor-like electrode materials are of nano-structured carbon materials, such as activated carbon (Act-C), carbon nanotubes (CNTs) and graphenes. These nanostructures of carbon are the preferred choice for making the ideally polarizable electrode because of their large surface area, porosity, stability over a wide potential window, and relatively low electrical resistance. In addition, pseudocapacitive materials including $\mathrm{MnO}_{2}, \mathrm{RuO}_{2}$ and conducting polymers can also be used as the capacitor-like electrode materials. These redox materials can provide high electrode capacitance, but relatively narrow potential windows in comparison with EDLC materials. However, it does not necessarily mean a small cell voltage when the redox material is used together with a counter electrode in a supercapattery. The cell voltage is determined by the potential window of the electrolyte used, and also the relative potential windows of the materials on both the positrode and negatrode. For example, the recent study of a hybrid cell with a $\mathrm{MnO}_{2}$ positrode, a $\mathrm{Li}$ metal negatrode and a combined solid and aqueous electrolytes revealed a cell voltage of $4.3 \mathrm{~V}$ [8].

Compared with the traditional supercapacitor comprising two EDLC electrodes, supercapattery uses the hybrid configuration including one redox electrode at least. However, it should be mentioned that combining a supercapacitor electrode and a redox electrode into one device could result in performance similar to that of the supercapacitor or battery. The former would be an example for supercapattery, while the latter could be recommended as supercabattery [9].

As for the redox electrode which may be battery-like or pseudocapacitive, a much wider choice of materials exists, from lead acid to metal/air batteries, but metal compounds such as $\mathrm{SnO}_{2}, \mathrm{MnO}_{2}$ and $\mathrm{LiFePO}_{4}$ are more practically and commercially available. The redox reactions based on these inorganic compounds contribute to the high charge storage in a supercapattery. Another type of redox materials for supercapattery is redox active polymers, some of which are the above 
mentioned conducting polymers. The most commonly used conducting polymers for charge storage purposes are polypyrrole (PPy), polyaniline (PAn) and poly(3,4-ethylenedioxythiophene) (PEDOT). They are in a good balance position between polymer plasticity and electronic conductivity. In common conditions, the characteristics of redox electrode materials will greatly affect the performance of the supercapattery. Composites comprising redox materials and carbon based skeleton materials have been considered to be promising for improving the performance of charge storage in supercapattery. In the recent decade, both the metal oxides and conducting polymers have been successfully composited with CNTs and graphenes. The redox materials in such composites still play an important role in the charge storage of a supercapattery cell.

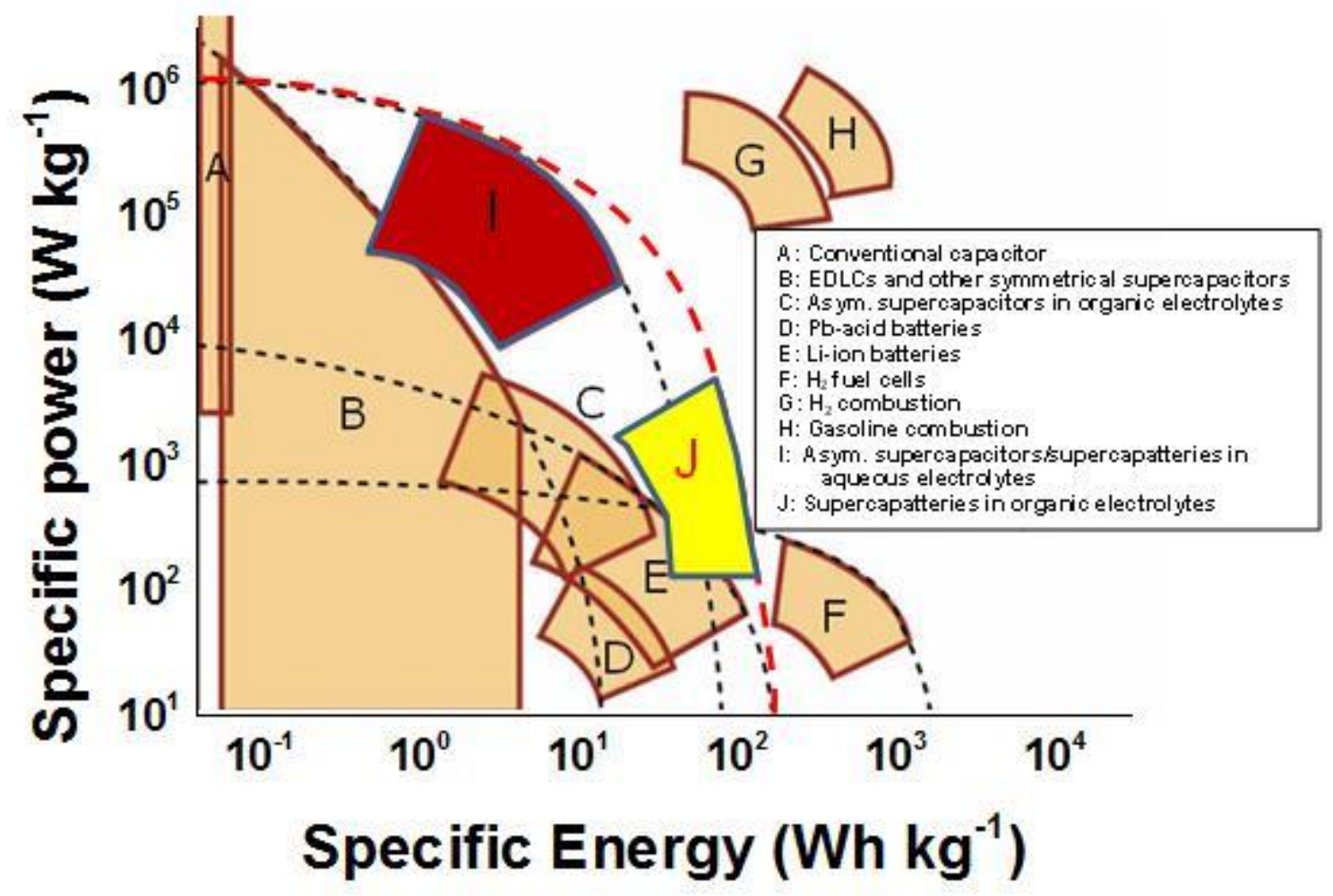

Fig. 1 Ragone plots of various electrochemical and internal combustion power devices [10-14].

According to definition, the redox electrode in the supercapattery can be either made from pseudocapacitive materials, e.g. $\mathrm{MnO}_{2}$ and PPy, despite of their capacitor-like behaviour, i.e. rectangular CVs, or a battery-like electrode which presents peak-shaped CVs. No matter if the CV 
of the redox electrode is rectangular or not (capacitor-like or not), the supercapattery will always show rectangular CVs as same as a capacitor. Fig. 1 and Table 1 compare the current status of different energy storage devices in terms of their energy and power performance [10-14]. Due to the use of redox materials, especially the battery electrode materials, supercapatteries with an organic electrolyte can output higher power than, and store a comparable amount of energy as Li ion batteries. In aqueous electrolytes, supercapatteries show smaller specific energy because of the smaller operational cell voltage, but they are advantageous in terms of specific power. Table 1 summarises various combinations of capacitive and faradaic electrode materials, and lists the reported performance of the electrochemical energy storage devices, including the supercapacitors [15-20], supercapatteries [5,8,17-22] and batteries [23].

Table 1 Summary of the electrochemical energy storage devices, including the energy storage type of the electrode materials, specific energy, specific power, and cycling life of the devices.

\begin{tabular}{|c|c|c|c|c|c|c|}
\hline \multirow{3}{*}{ Device } & \multicolumn{6}{|c|}{ Supercapattery (Supercabattery) } \\
\hline & \multicolumn{3}{|c|}{ Supercapacitor } & \multirow{2}{*}{\multicolumn{2}{|c|}{ Hybrid }} & \multirow{2}{*}{ Battery } \\
\hline & EDLC & Pseudo & pacitor & & & \\
\hline \multirow{3}{*}{ Electrode Material } & NFCS & NFCS & CFS & NFCS & CFS & NCFS \\
\hline & + & + & + & + & + & + \\
\hline & NFCS & CFS & CFS & NCFS & NCFS & NCFS \\
\hline $\begin{array}{l}\text { Specific energy } \\
\left(\mathrm{Wh} \mathrm{kg}^{-1}\right)\end{array}$ & $\begin{array}{l}6.7[15], \\
10.2[16]\end{array}$ & $\begin{array}{l}3.6[17], \\
14.3[18]\end{array}$ & $26.6[19]$ & $\begin{array}{l}204[21], \\
230[5],\end{array}$ & $\begin{array}{c}103[22], \\
114[8]\end{array}$ & $250[23]$ \\
\hline $\begin{array}{l}\text { Max specific power } \\
\left(\mathrm{kW} \mathrm{kg}^{-1}\right)\end{array}$ & $\begin{array}{l}111.6 \\
{[15]}\end{array}$ & $\begin{array}{l}24.7[17], \\
0.68[18]\end{array}$ & 13 [19] & $55[21]$ & $56[22]$ & $1.5[23]$ \\
\hline Cycling life (cycles) & $\begin{array}{c}>10,000 \\
{[16]}\end{array}$ & $\begin{array}{c}>5,000 \\
{[17]}\end{array}$ & $\begin{array}{c}>5000 \\
{[19,20]}\end{array}$ & $\begin{array}{c}>1000 \\
{[21]}\end{array}$ & $\begin{array}{c}>1000 \\
{[22]}\end{array}$ & $\begin{array}{c}<1200 \\
{[23]}\end{array}$ \\
\hline
\end{tabular}

NFCS: Non-Faradaic Capacitive Storage = EDLC Storage

CFS: Capacitive Faradaic Storage $=$ Pseudocapacitive Storage

NCFS: Non-Capacitive Faradaic Storage = Battery-Type Storage 
This review paper mainly introduces the progress of redox electrode materials for supercapatteries. Most examples are chosen from the work done by the authors' research group. Recent progress on the high energy capacity electrode materials is also discussed.

\section{Inorganic redox electrode materials for supercapattery}

As a unique example of inorganic redox materials, amorphous hydrous ruthenium oxide $\left(\mathrm{RuO}_{2} \cdot n \mathrm{H}_{2} \mathrm{O}\right)$ exhibits excellent pseudocapacitive behaviour with large specific capacitance (almost $10^{3} \mathrm{~F} \mathrm{~g}^{-1}$ ) and great reversibility $[24,25]$, but the low abundance and high cost of this precious metal element prevent its commercial applications. There is a strong desire for developing costeffective pseudocapacitive electrode materials. $\mathrm{MnO}_{2}$ is also a good candidate for the pseudocapacitive electrode materials. A high specific capacitance value of $698 \mathrm{~F} \mathrm{~g}^{-1}$ was reported for a thin film of $\mathrm{MnO}_{2}$ [26]. However, this thin film of $\mathrm{MnO}_{2}$ still cannot be commercially applied, because increasing the film thickness will not only increase the total charge storage capacity but also cause a dramatically increase of the resistance. Several attempts have been introduced in previous research work. One of these is redox deposition of $\mathrm{MnO}_{2}$ on carbon based materials [11,20,27,28]. Reaction (1) was considered to be responsible for the redox deposition of $\mathrm{MnO}_{2}$ from $\mathrm{KMnO}_{4}$ on the surface of carbon based materials.

$$
4 \mathrm{MnO}_{4}^{-}+3 \mathrm{C}+\mathrm{H}_{2} \mathrm{O} \longleftrightarrow 4 \mathrm{MnO}_{2}+\mathrm{CO}_{3}^{2-}+2 \mathrm{HCO}_{3}^{-}
$$

When $\mathrm{KMnO}_{4}$ was reduced to $\mathrm{MnO}_{2}$ on a graphite disc electrode surface by this method, the cyclic voltammograms (CVs) of the coated electrode exhibited typical pseudocapacitive behaviour in various neutral aqueous electrolytes $\left(0.5 \mathrm{~mol} \mathrm{~L}^{-1} \mathrm{LiCl}, 0.5 \mathrm{~mol} \mathrm{~L}^{-1} \mathrm{LiClO}_{4}, 0.5-2.0 \mathrm{~mol} \mathrm{~L}^{-1} \mathrm{NaCl}\right.$, 0.1-0.25 mol L $\mathrm{La}_{2} \mathrm{SO}_{4}$ and 0.5-1.0 mol L-1 $\mathrm{KCl}$ ) [27]. The coated electrode was fabricated by placing a graphite disc electrode vertically in a beaker containing a freshly prepared $\mathrm{KMnO}_{4}+$ $\mathrm{H}_{2} \mathrm{SO}_{4}$ solution which was continuously stirred during the deposition. The deposition was carried out at room temperature for durations of different times. Table 2 lists the results of specific 
capacitance calculated from CVs recorded in various neutral aqueous solutions of alkali metal salts, showing a clear trend of the capacitance increasing with decreasing the size of the alkali metal cation. The capacitance of the coating in $0.5 \mathrm{~mol} \mathrm{~L}^{-1} \mathrm{LiCl}$ increased to $45 \mathrm{mF} \mathrm{cm}^{2}$ with the deposition time up to $60 \mathrm{~min}$, obeying very well the logarithm law. In addition, continuously cycling the potential of the coated electrode up to 1000 cycles only caused very little change in capacitance. Although the specific capacitance of the $\mathrm{MnO}_{2}$ coating on the graphite disc electrode by redox deposition was not reported, this study accurately anticipated the following "redox deposition" of $\mathrm{MnO}_{2}$ on high surface area carbon materials, such as CNTs [28] and Act-C.

Table 2 The capacitance of a redox-deposited $\mathrm{MnO}_{x}$ film on graphite in different electrolytes ${ }^{\mathrm{a}}$ [27].

\begin{tabular}{cccccccccc}
\hline Electrolyte & $\mathrm{LiCl}$ & $\mathrm{LiClO}_{4}$ & $\mathrm{NaCl}$ & $\mathrm{NaCl}$ & $\mathrm{NaCl}$ & $\mathrm{Na}_{2} \mathrm{SO}_{4}$ & $\mathrm{Na}_{2} \mathrm{SO}_{4}$ & $\mathrm{KCl}$ & $\mathrm{KCl}$ \\
$\left(\mathrm{mol} \mathrm{L}^{-1}\right)$ & 0.5 & 0.5 & 0.5 & 1.0 & 2.0 & 0.1 & 0.25 & 0.5 & 1.0 \\
\hline $\begin{array}{c}\text { Capacitance } \\
\left.(\mathrm{mF} \mathrm{cm})^{-2}\right)\end{array}$ & 8.9 & 8.3 & 7.1 & 5.7 & 5.6 & 7.6 & 7.6 & 6.8 & 5.8 \\
\hline
\end{tabular}

${ }^{\text {a }}$ All capacitance data were derived from the stable cyclic voltammograms of the same electrode that was obtained after 2 min redox deposition. The electrode was thoroughly washed in water between experiments.

A very basic work on the nanoscale micro-electrochemical cells on CNTs [28] has been done to investigate the redox deposition of $\mathrm{MnO}_{2}$ and to confirm the correctness of reaction (1) for the process. Acid treated CNTs were used for replacing the graphite disc in this later work. Compared to other carbon based materials, CNTs have relatively consistent tubular structures and hence allow a more reliable comparison of the sample before and after the redox deposition. According to typical HRTEM and TEM images of the deposited $\mathrm{MnO}_{2}$ on the CNT, as shown respectively in Fig. 2c and 2d, nanocrystalline $\mathrm{MnO}_{2}$ was found both on the surface and in the cavity, but not at the open end of individual CNTs. A micro-electrochemical cell mechanism was postulated as schematically illustrated in Fig. 2a and 2b [28]. At the initial stage as shown in Fig. 2a, the directcontact reaction between $\mathrm{MnO}_{4}{ }^{-}$and CNT defect and/or tube end, leads to a local increase of $\mathrm{pH}$ 
and depletion of $\mathrm{MnO}_{4}{ }^{-}$. Both of these factors are unfavourable for $\mathrm{MnO}_{4}{ }^{-}$reduction. The $\mathrm{MnO}_{2}$ precipitation at this stage can be found at or near the defect site.
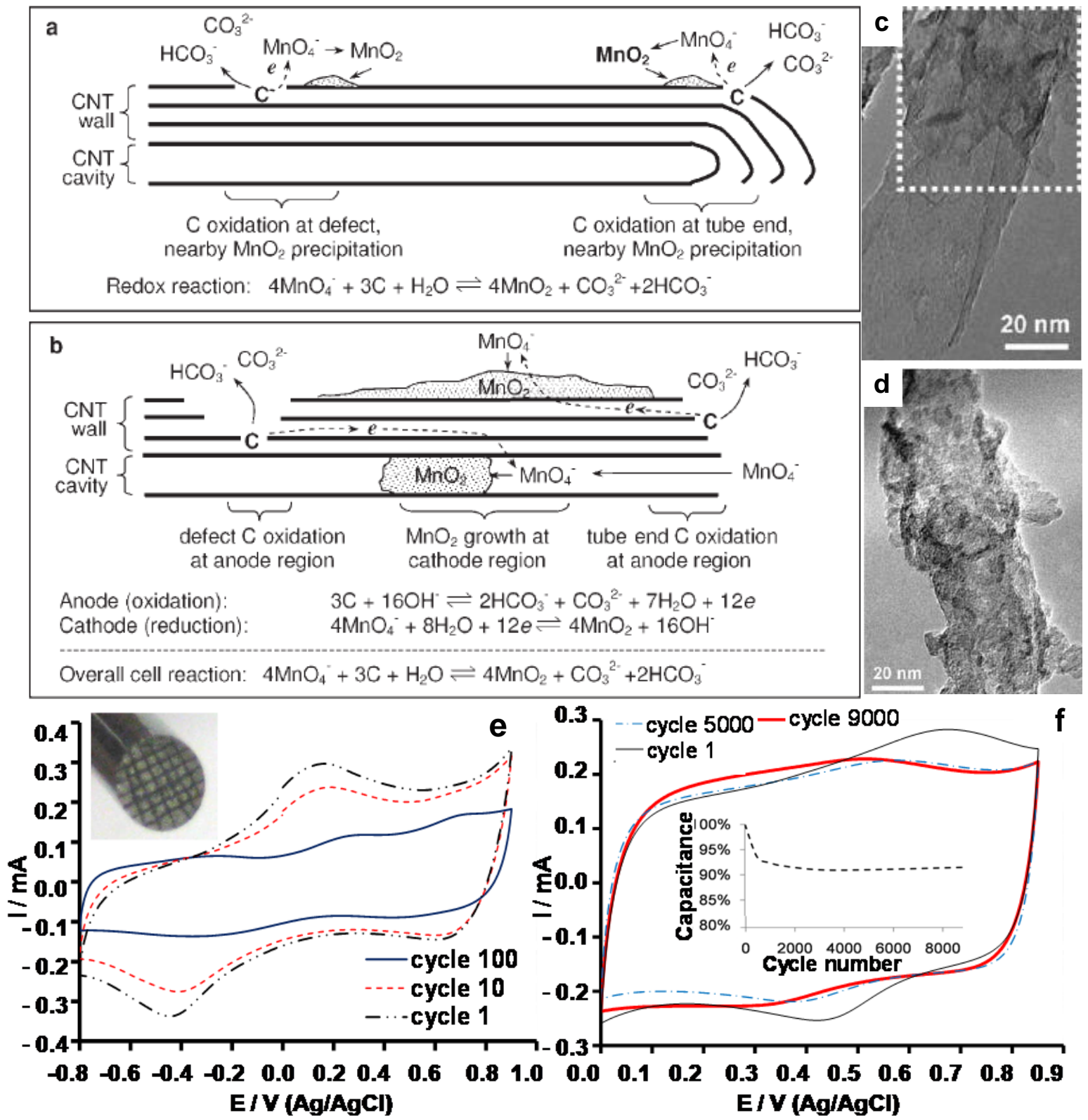

Fig. 2 Schematic illustration of redox deposition. (a) Initial stage, (b) later stage; and (c) typical TEM images of (c) a corroded CNT ends with selective coated nanocrystalline $\mathrm{MnO}_{2}$ and (d) a CNT with $\mathrm{MnO}_{2}$ coating (50 w. \% $\mathrm{MnO}_{2}$ ) [28]. (e), (f) CVs of CNT-65 w\% $\mathrm{MnO}_{2}$ in $0.5 \mathrm{M} \mathrm{KCl}$ in the indicated potential windows and number of potential cycles. The composite powder was loaded on a graphite disc trench electrode, see the inset photo in (e). The inset in (f) plots the capacitance retention against the number of potential cycles in a long term charging-discharging test [20] 
At the later stage of the redox deposition, the good electronic conductivity of CNTs makes the defect and another location on the CNT wall to be the anode and cathode, respectively. The electron transfer in this stage constitutes the micro-electrochemical cell postulation, which is further proven by the TEM observation in Fig. 2c. The CNT in this image shows clearly an open end without any $\mathrm{MnO}_{2}$ coating. While further up from the opening, nanocrystallites of $\mathrm{MnO}_{2}$ were present. This phenomenon can hardly be explained by the chemical precipitation mechanism, but supports the micro-electrochemical cell postulation mentioned above.

CVs of the CNT-65 w\% $\mathrm{MnO}_{2}$ sample under different conditions are shown inn Fig. 2e and $2 \mathrm{f}$ [20]. The specific capacitance was found to be $144 \mathrm{~F} \mathrm{~g}^{-1}$ on average [28]. The area-normalised capacitance went beyond $5 \mathrm{~F} \mathrm{~cm}^{-2}$ which is very high in comparison with most reported results, e.g. the data in Table 2. In order to utilise the CNT- $\mathrm{MnO}_{2}$ composite in a real energy storage device, several attempts have been made, including asymmetrical cell design comprising a $\mathrm{CNT}-\mathrm{MnO}_{2}$ positrode and a CNT- $\mathrm{SnO}_{2}$ negatrode [11] and symmetrical cell with two $\mathrm{CNT}-\mathrm{MnO}_{2}$ electrodes [20]. For the asymmetrical cell, the operating voltage of the single cell was up to $1.70 \mathrm{~V}$ in the 2.0 mol L $\mathrm{L}^{-1} \mathrm{KCl}$ aqueous solution without invoking water decomposition. The reason could be the high over potential for hydrogen evolution on the $\mathrm{CNT}-\mathrm{SnO}_{2}$ negatrode. The specific energy of the asymmetrical cell at a current of $0.04 \mathrm{~mA}$ reached $20.3 \mathrm{Wh} \mathrm{kg}^{-1}$, and the maximum specific power was $143.7 \mathrm{~kW} \mathrm{~kg}$, which was fairly high for an aqueous asymmetrical supercapacitor or supercapattery at the time when the work was published [11]. The capacitance loss of the asymmetrical cell was less than $8 \%$ even after 1000 charge-discharge cycles. A stack of nine asymmetrical cells was also built and achieved a total stack voltage of $10 \mathrm{~V}$ with a satisfactorily small iR drop. On the other hand, the symmetrical cell test ran 9000 charge-discharge cycles, after that only $9 \%$ capacitance loss was observed, see Fig. 2f [20]. The stack study on the symmetrical cell also revealed that it was effective to use bipolar electrodes for serial connections of individual aqueous $\mathrm{CNT}-\mathrm{MnO}_{2}$ symmetrical cells to achieve desirable energy storage capacity and power performance. Some performance data of the single cell and two-cell stack are listed in Table 3 [20]. 
In recent research of the pseudocapacitance of $\mathrm{MnO}_{2}$ based composites, some reported specific capacitance values were higher than $350 \mathrm{~F} \mathrm{~g}^{-1}$ [29-31]. This improvement is mainly caused by the special carbon skeleton structure [29], chemical treatment of $\mathrm{MnO}_{2}$ [30] and morphology and crystallinity-control in $\mathrm{MnO}_{2}$ synthesis [31]. However, it can be noticed that in some examples the calculated specific capacitance as derived from CVs was about $130 \%$ of the value measured by galvanostatic charge-discharge (GCDs) [29]. Most composites of $\mathrm{MnO}_{2}$-carbon exhibit satisfactory capacitor features such as rectangular CVs and linear GCDs [11,20,28-31]. However, not all metal oxides or their carbon composites behave like a capacitor, particularly presenting peak shaped CVs and non-linear GCDs. Although such redox materials are still very promising for energy storage applications, the capacitor equations are no longer valid in these situations and may lead to some misinterpretation of the data. Simply speaking, the capacitor equations can only be applied when the CVs or GCDs present features of a capacitor. More detailed discussion can be found in previous reviews on supercapacitor $[9,32]$.

Table 3 Performance comparison of symmetrical single cell and stack [20].

\begin{tabular}{ccc}
\hline Symmetrical CNT-60 w. \% $\mathrm{MnO}_{2}$ & Single cell & Two-cell stack \\
\hline Capacitance $\left(\mathrm{CV}, 10 \mathrm{mV} \mathrm{s}^{-1}\right)$ & $0.49 \mathrm{~F}$ & $0.21 \mathrm{~F}$ \\
Capacitance (EIS, 0.0 V) & $0.53 \mathrm{~F}$ & $0.23 \mathrm{~F}$ \\
Capacitance (GCD, $\left.10 \mathrm{~mA} \mathrm{~cm}{ }^{-2}\right)$ & $0.50 \mathrm{~F}$ & $0.20 \mathrm{~F}$ \\
Applied cell voltage & $0.9 \mathrm{~V}$ & $1.8 \mathrm{~V}$ \\
ESR (from EIS at 0 V) & $0.62 \Omega$ & $1.08 \Omega$ \\
Charge- transfer resistance & $0.55 \Omega \mathrm{cm}^{-2}$ & $1.06 \Omega \mathrm{cm}^{-2}$ \\
Coulombic efficiency $\left(10 \mathrm{~mA} \mathrm{~cm}{ }^{-2}\right)$ & $96.6 \%$ & $95.6 \%$ \\
\hline
\end{tabular}

$\mathrm{CV}=$ Cyclic voltammograms; EIS = Electrochemical impedance spectra $; \mathrm{GCD}=$ Galvanostatic charge-discharge; ESR= Equivalent Series Resistance. 
Recent studies have also confirmed that both aqueous and non-aqueous supercapatteries could be fabricated using Li metal [5, 8] and Li ion battery materials [21,33,35] as the electrode materials. An aqueous supercapattery (called hybrid electrochemical capacitor by the authors) consisting of a $\mathrm{MnO}_{2}$ positrode and a $\mathrm{Li} / \mathrm{LISICON} / \mathrm{PEO}-\mathrm{LiTFSI} / \mathrm{Li}^{+}$negatrode had achieved a specific energy value of $114 \mathrm{Wh} \mathrm{kg}^{-1}$ at a cell voltage of $4.3 \mathrm{~V}$ [8]. The Li/LISICON/PEO-LiTFSI/Li ${ }^{+}$electrode was a multi-layered Li electrode, which consisted of the Li metal, a LISICON-type solid glass ceramic as the water-stable solid electrolyte, and a buffer layer consisting of polyethylene oxide with $\mathrm{Li}\left(\mathrm{CF}_{3} \mathrm{SO}_{2}\right)_{2} \mathrm{~N}$ polymer electrolyte (PEO-LiTFSI) between the Li metal and the solid electrolyte. When $\mathrm{MnO}_{2}$ was replaced by $\mathrm{RuO}_{2}$ as the positrode, the specific energy of the device was increased to $520 \mathrm{Wh} \mathrm{kg}^{-1}$ at a cell voltage of $3.8 \mathrm{~V}$ [8]. However, the current density of the aforementioned device was only $0.255 \mathrm{~mA} \mathrm{~cm}$, which was limited by the solid/liquid interphase. As aforementioned, $\mathrm{Ru}$ based precious metal materials are too expensive for commercial applications. Another supercapattery constructed by combing $\mathrm{Fe}_{3} \mathrm{O}_{4}$-graphene nanocomposite based negative electrode and 3D graphene (3D porous graphene-based carbon material) based positrode exhibited specific energy of $65-204 \mathrm{Wh} \mathrm{kg}^{-1}$ and specific power from 4600 to $55 \mathrm{~W} \mathrm{~kg}^{-1}$, utilising $\mathrm{Li}^{+}$ion intercalation [21]. A very recent study demonstrated a supercapattery based on an activated carbon positrode and a $\mathrm{Li} / \mathrm{Li}^{+}$negatrode using an ionic liquid electrolyte, 1-butyl-1-methylpyrrolidinium tri(pentafluoroethyl)trifluorophosphate (BMPyrrFAP) containing gamma-butyrolactone $(\gamma-\mathrm{GBL})$ and $\mathrm{LiClO}_{4}$ [5]. Its specific energy reached $230 \mathrm{Wh} \mathrm{kg}^{-1}$ under the galvanostatic charge-discharge current density of $1 \mathrm{~mA} \mathrm{~cm}{ }^{-2}$, which is the highest value for supercapatteries that have ever been reported in the literature. The galvanostatic charge-discharge curve is shown in Fig. 3 [5]. It is acknowledged that in addition to supercapattery, phrases such as "hybrid electrochemical capacitor" and "lithium ion capacitor" are used the literatures $[8,21,33,34]$. This situation in the literature is understandable, although the authors are of the opinion that supercapattery will make a generic term that can represent all types of hybrid devices that aim to combine the merits of a battery electrode and a supercapacitor electrode. 


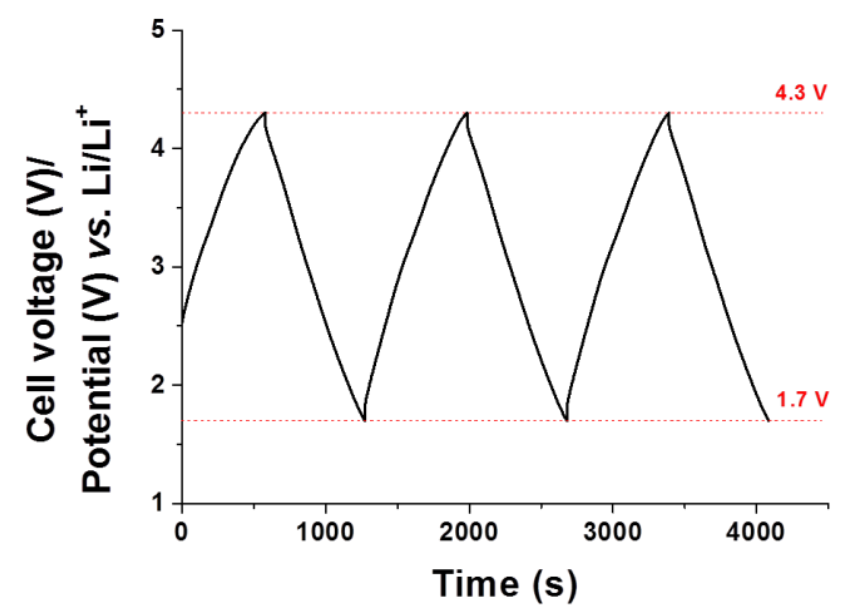

Fig. 3 Galvanostatic charge-discharge curves of a demonstrative supercapattery cell under a current density of $1 \mathrm{~mA} \mathrm{~cm}^{-2}[5]$.

\section{Conducting polymer based redox electrode materials for supercapatteries}

Another type of redox electrode materials for uses in supercapattery is conducting polymers. Similar to transition metal oxides, conducting polymers can boost the capacitance since they are redox active and can utilise fast and reversible electron transfer or Faradic reactions for charge storage within the electrode. Although a conducting polymer itself possesses the capacitive characteristics, it performs often below expectation when used alone without any morphology control or hybridisation with another material. For example, pure PEDOT could show a rectangular shape $\mathrm{CV}$ at $200 \mathrm{mV} \mathrm{s}^{-1}$, but the symmetrical PEDOT supercapacitor offered fairly specific energy of 1 to $4 \mathrm{Wh} \mathrm{kg}^{-1}$, while the goal was set to be $15 \mathrm{Wh} \mathrm{kg}^{-1}$ almost twenty years ago [35]. In recent years, interests have been focused on combining CNTs, graphene or other skeleton materials with conducting polymers. This route is an effective approach to overcoming the drawbacks of conducting polymers in mechanical strength and conductivity while maintaining their large pseudocapacitance.

\subsection{Electrochemical co-deposition}

Electrochemical co-deposition of conducting polymers and CNTs to form the composite 
directly on the electrode has attracted a lot of attentions in recent decade [17,18,36-47]. The ionised CNTs via partial oxidation in acid were used as the dopants when the conducting polymers was electrochemically deposited on the surface of the electrode. The PPy composited with CNTs was first electrochemically co-deposited in a stabilised aqueous solution containing the ionised CNTs and pyrrole monomers [36]. CNTs acted as the supporting electrolyte in the solution and also the electron conductive dopants in the CNT-PPy hybrid. Fig. 4a shows an image of high-resolution transmission electron microscopy of the electrochemically co-deposited CNT-PPy hybrid.
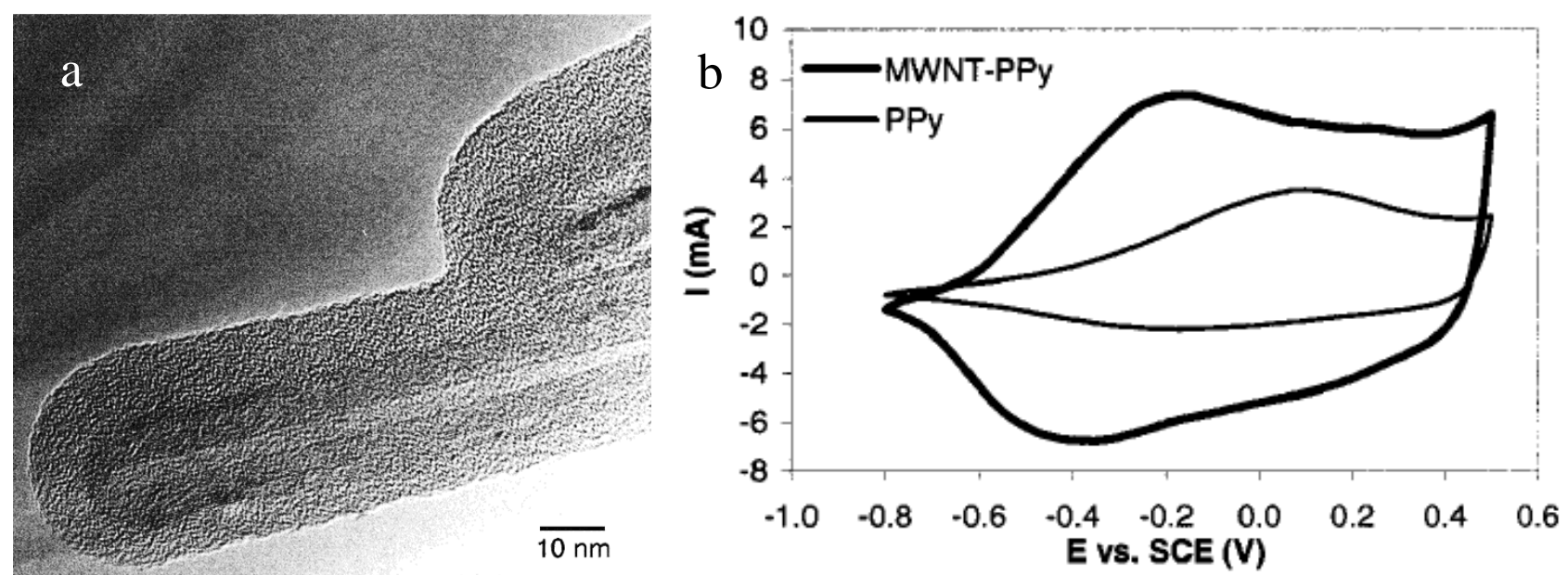

Fig. 4 (a) High-resolution transmission electron micrograph of electrodeposited CNT-PPy hybrids, showing two almost parallel nanotubes coated by a layer of PPy [36]. (b) CVs of the CNT-PPy composite and pure PPy films prepared using similar conditions [37].

Such co-deposited CNT-PPy hybrids have been investigated by various experimental methods, including CV [36-42,44], electrochemical impedance spectroscopy (EIS) [36-38,41,43-45] and electrochemical quartz crystal microbalance (EQCM) [39, 45]. Typical CVs of the CNT-PPy hybrid are shown in Fig. 4b. First, the CV current of the CNT-PPy film was about twice of that of the pure polymer. Second, the peak potentials of the CNT-PPy film were about $200 \mathrm{mV}$ more negative than those of the pure PPy film, confirming the dopant role of anionic CNTs. Third, the CV currents of the CNT-PPy hybrid were noticeably larger than those of the pure polymer at the more negative 
potentials where the polymer either alone or in the composite was in the reduced states with low conductivity. This is indicating the conductive contribution from CNTs in the composite film. The capacitance per mass and per geometric area of the same electrode in Fig. 4b were as high as $192 \mathrm{~F}$ $\mathrm{g}^{-1}$ and $1.0 \mathrm{~F} \mathrm{~cm}^{-2}$, respectively [37].

Similar to the CNT-PPy composite, PAn functionalized with CNTs were electrochemically codeposited in a $\mathrm{HCl}$ solution containing aniline and CNTs [41]. CVs and EIS indicated that these composite films had similar electrochemical response rates to the pure PAn films, but a lower resistance and much improved mechanical integrity. The capacitance of the composite films per geometric area of the original electrode reached $3.5 \mathrm{~F} \mathrm{~cm}^{-2}$, while the pure PAn film similarly prepared was $2.3 \mathrm{~F} \mathrm{~cm}^{-2}$ [41].

Table 4 Electrochemical data of thin films of conducting polymers and their composites with acid treated CNTs [43].

\begin{tabular}{ccccccc}
\hline & CNT-PAn & PAn & CNT-PPy & PPy & CNT-PEDOT & PEDOT \\
\hline Deposition charge, $Q_{\text {dep }}(\mathrm{mC})$ & 6.5 & 6.5 & 6.5 & 6.5 & 6.5 & 6.5 \\
Capacitive potential range, $U(\mathrm{~V})$ & 0.65 & 0.65 & 1.00 & 1.00 & 1.00 & 1.00 \\
CV capacitance, $C_{\mathrm{CV}}(\mathrm{mF})$ & 1.31 & 1.20 & 1.44 & 0.51 & 1.17 & 0.54 \\
EIS capacitance, $C_{\mathrm{EIS}}(\mathrm{mF})$ & 1.27 & 1.05 & 1.10 & 0.47 & 0.79 & 0.39 \\
EIS bias $(\mathrm{V}$ vs. $\mathrm{Ag} / \mathrm{AgCl})$ & 0.60 & 0.60 & 0.40 & 0.40 & 0 & 0 \\
$C_{\mathrm{EIS}} / Q_{\text {dep }}(\mathrm{F} / \mathrm{C})$ & 0.195 & 0.162 & 0.169 & 0.072 & 0.122 & 0.060 \\
Knee frequency $(\mathrm{Hz})$ & 66.0 & 66.0 & 829.0 & 49.4 & 268.0 & 28.1 \\
Z' at $0.01 \mathrm{~Hz}(\Omega)$ & 52.5 & 58.4 & 212 & 397 & 200 & 581 \\
\hline
\end{tabular}

Each film was electrochemically deposited on a Pt disc electrode with a surface area $=0.02 \mathrm{~cm}^{2}$.

As to PEDOT, its solutions with acetonitrile or a mixture of acetonitrile as the solvent were used in the electrochemical co-deposition with CNTs [42, 43, 46]. In the solution, additional supporting electrolyte was added. It was found that the CNTs in the mixture of acetonitrile and 
water helped formation of sufficiently stable emulsions that enabled the co-deposition of the CNTPEDOT composites $[42,43]$. There was a stable period after the emulsion was formed by sonication. Only after a sufficiently long time, the emulsion would eventually undergo phase separation [43]. A detailed comparison of the electrochemically co-deposited CNT-conducting polymer and pure polymer is listed in Table 4.

EQCM can measure the accurate mass change of species on the electrode, the CVs and EQCM were combined to investigate the electro-deposited CNT-PPy and pure PPy coatings in $\mathrm{KCl}$ and PPy $\mathrm{NBt}_{4} \mathrm{Br}$ (tetrabutylammonium bromide) solutions [39]. Fig. 5 compares the CVs and masspotential plots of the PPy and CNT-PPy coatings. Clearly, cation expulsion and anion uptake were observed for the CNT-PPy coating in $\mathrm{KCl}$ (Fig. 5c and 5d), whilst only anion uptake and expulsion
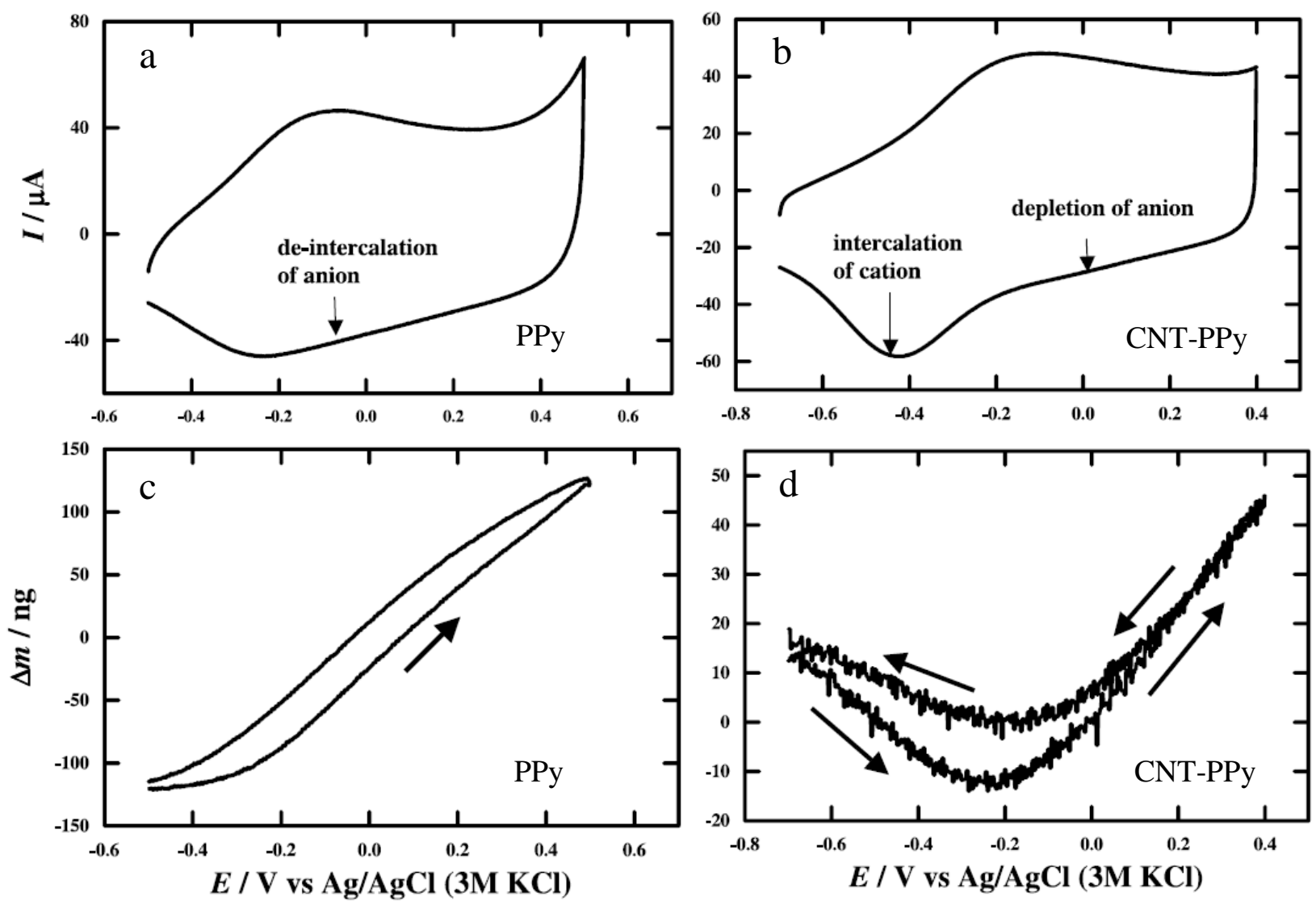

Fig. 5 CVs (a,b) and the simultaneously recorded mass-potential plots (c,d) of pure PPy in 0.5 mol $\mathrm{L}^{-1}$ tetrabutylammonium bromide (a,c) and the CNT-PPy composite in $0.5 \mathrm{~mol} \mathrm{~L}^{-1} \mathrm{KCl}$. Potential scan rate: $50 \mathrm{mV} \mathrm{s}^{-1}$. Both the PPy and CNT-PPy coatings were electro-deposited [39]. 
were seen for the PPy coating in $\mathrm{NBt}_{4} \mathrm{Br}$ (Fig. 5a and 5b). These phenomena and differences are strong evidence that the negatively charged CNTs partially doped the PPy.

Based on the CV and the mass of the coating, the value of specific capacitance of CNT-PPy was calculated to be about $200 \mathrm{~F} \mathrm{~g}^{-1}$, which was lower than that of the similarly grown PPy coating, $240 \mathrm{~F} \mathrm{~g}^{-1}$ [39]. This difference can be qualitatively explained by the inclusion of the redox inert CNTs in the composite coating, but more quantitative analysis is pending for the knowledge of the CNT content in the co-deposited composite. The specific capacitance of electro-deposited PAn and PEDOT thin coatings were also determined by EQCM to be 530 and $92 \mathrm{~F} \mathrm{~g}^{-1}$, respectively [46].

An important application of EQCM is to help determine more accurately the potential at which the electro-deposition starts. In this way, thick, coherent and porous PEDOT coatings were prepared under potentiostatic conditions, and a linear correlation between the deposition charge and the area normalised electrode capacitance was observed. It was reported that the area normalised capacitance could reach beyond $5 \mathrm{~F} \mathrm{~cm}^{-2}$ [45], which very significant for a redox material with relatively low specific capacitance.

Alongside conducting polymers are a large family of redox active polymers, such as poly(oaminophenol) (PoAP) and poly(m-phenylenediamine) (PmPD) [47], which have relatively low conductivity. These polymers can also be electro-deposited into relatively thin films, but when the film becomes thicker, it becomes too resistive and the electro-polymerisation will cease. Addition of anionised CNTs in the monomer solution helped overcome the conductivity barrier, and enabled continuation of the electrodeposition process, as illustrated in Fig. 6a. The obtained CNT-PoAP composite films exhibited well peak-shaped CVs, in contrast to those composite of CNT-PAn or CNT-PPy. The CVs of CNT-PoAP and CNT-PAn are compared in Fig. 6b. However, the structures were very much comparable between these electro-deposited composites of CNTs with conducting polymer and non-conducting polymer, as shown in Fig. $6 \mathrm{c}$ and $6 \mathrm{~d}$, suggesting a similar mechanism of co-deposition. Combining a CNT-PoAP negatrode and a CNT-PAn positrode in $1.0 \mathrm{~mol} \mathrm{~L}^{-1} \mathrm{HCl}$ led to the successful demonstration of a whole polymer supercapattery that exhibited a working cell 
voltage up to $1.2 \mathrm{~V}$, in contrast to the $0.6 \mathrm{~V}$ cell voltage for a symmetrical cell with CNT-PAn as both the positrode and negatrode in the same electrolyte.
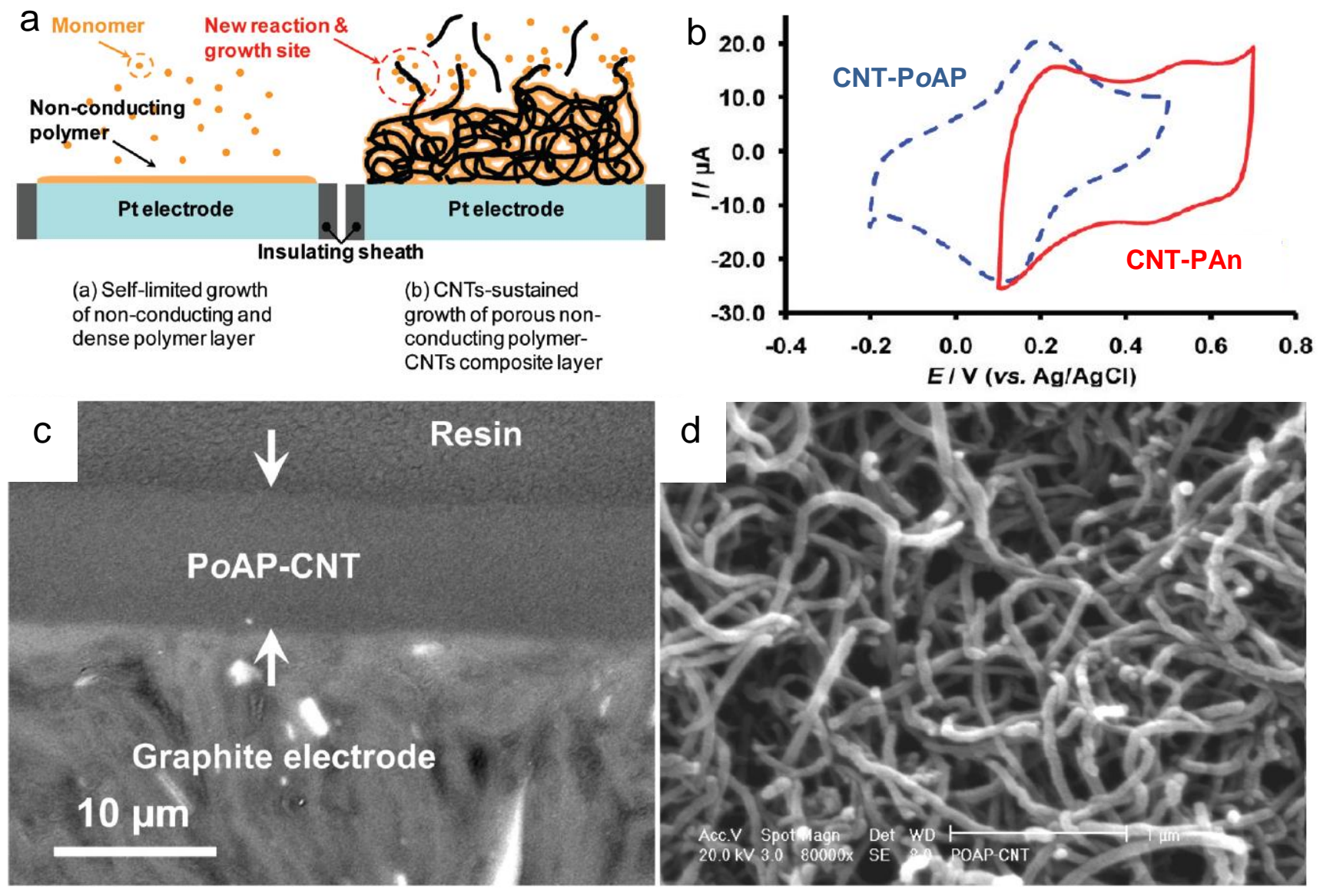

Fig. 6 (a) Schematic illustration of the electrodeposition of redox active non-conducting polymer (left) and electro-co-deposition of CNT-non-conducting polymer (right) in which the interconnected CNTs represent the electrode sites where further electro-polymerisation continues. (b) CVs of electro-co-deposited composite of CNT-PAn (red solid line) and CNT-PoAP in $1.0 \mathrm{~mol} \mathrm{~L}^{-1} \mathrm{HCl}$. Scan rate: $50 \mathrm{mV} \mathrm{s}^{-1}$ [47]. (c) BSE-SEM image of the cross-section, and (d) SEM image of the porous structure of an electro-co-deposited CNT-PoAP film on a graphite electrode [47].

\subsection{Chemical preparation}

Although the electrochemically synthesised CNT-PPy films performed amicably and were ideal for the lab work because of their electrochemical properties, mass-production of these CNT-PPy films could be challenging to achieve. A new and promising approach was recently reported that 
uses an electrolyser with seriously connected bipolar electrodes for simultaneous deposition of conducting polymer in multiple cells [18]. Alternatively, the chemical synthesis of composites of CNT and conducting polymers is also very popular in laboratory because of the anticipated convenience and readiness for scaling up. The reported synthesis process was very similar to that used for synthesis of pure conducting polymers, but required the presence of homogeneously dispersed CNTs in the reaction solution before and during the chemical polymerization $[17,48]$. Chemical polymerization of the conducting polymers with CNTs was affected by many factors, including $\mathrm{pH}$, relative concentration of reactants, polymerization temperature and time, as well as the choice of oxidant and protonic acids. For example, the amount of solvent used in the CNTs suspension could affect the morphology of the synthesised CNT-PPy composite as shown in Fig. 7a and $7 \mathrm{~b}$ [17]. The sample show in Fig. 7a could be suspended in water, while the one shown in Fig. $7 \mathrm{~b}$ could not be suspended in aqueous solution and exhibited poor capacitive performance.

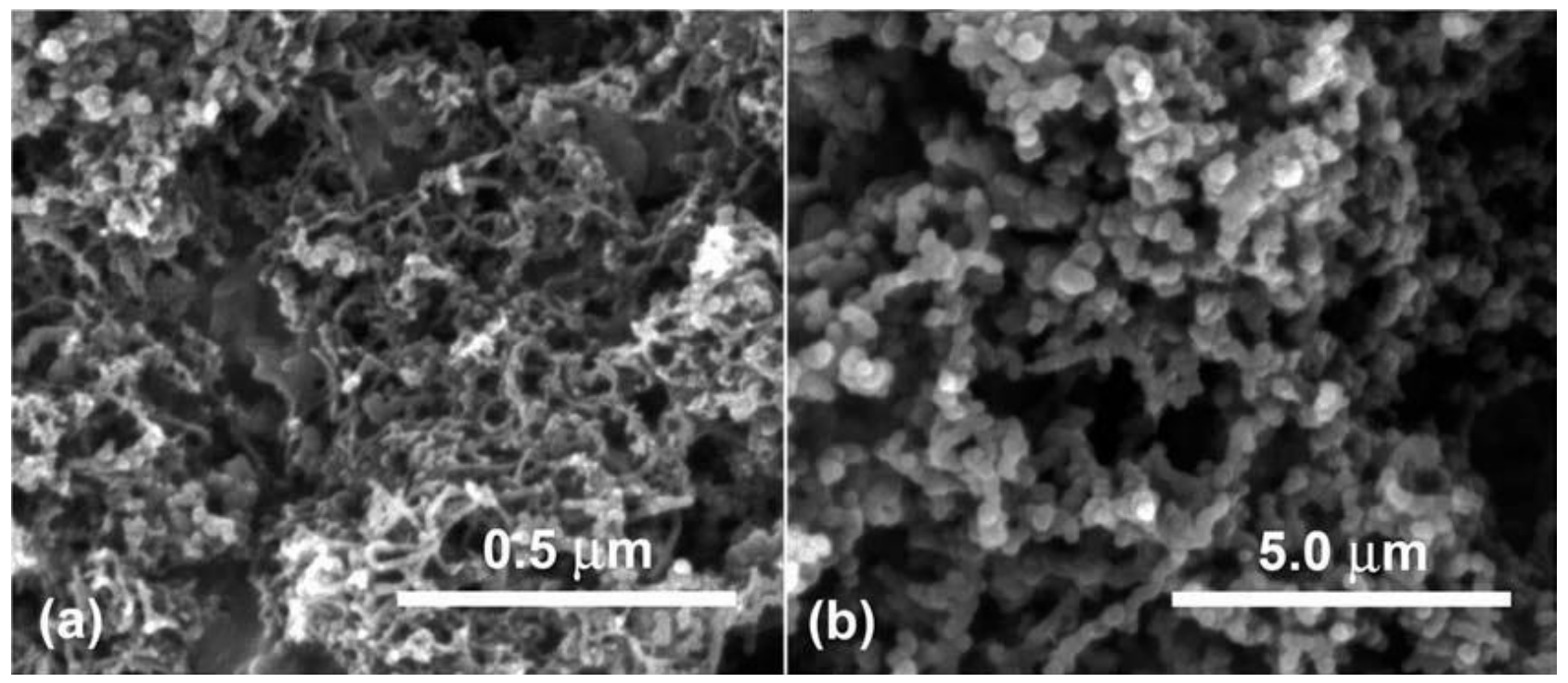

Fig. 7 SEM images of the CNT-PPy nanocomposites synthesised via chemical oxidation of the monomer by $\mathrm{FeCl}_{3}$ in (a) $500 \mathrm{~mL}$ and (b) $100 \mathrm{~mL}$ deionized water [48].

The disadvantage of chemical synthesis is that it often produces a powdery product that requires further steps for fabrication of the electrode. A laboratory attempt to screen print the 
chemically synthesised CNT-PPy or CNT-PAn powder succeeded in producing the stable ink and also thick coatings of the composite material onto an electrode plate (titanium) as shown in Fig. 8 . However, the study also revealed a main challenge [48]. It is to find a suitable binder and possibly a surfactant that can help disperse the CNT-conducting polymer powder into a stable printing ink. It was found in the initial attempt that the addition of the binder had to be more than $15 \mathrm{wt} \%$ of the active materials, so that the ink could work properly with the screen printer. Because of the nonconducting and non-active nature of the binder (and surfactant if added), the printed material was also more resistive than the electro-co-deposited counterpart, and hence could not perform satisfactorily in the following electrochemical tests. More effort is obviously needed to identify and develop a suitable route for fabrication of the chemically synthesised CNT-conducting polymer powder into the electrode.
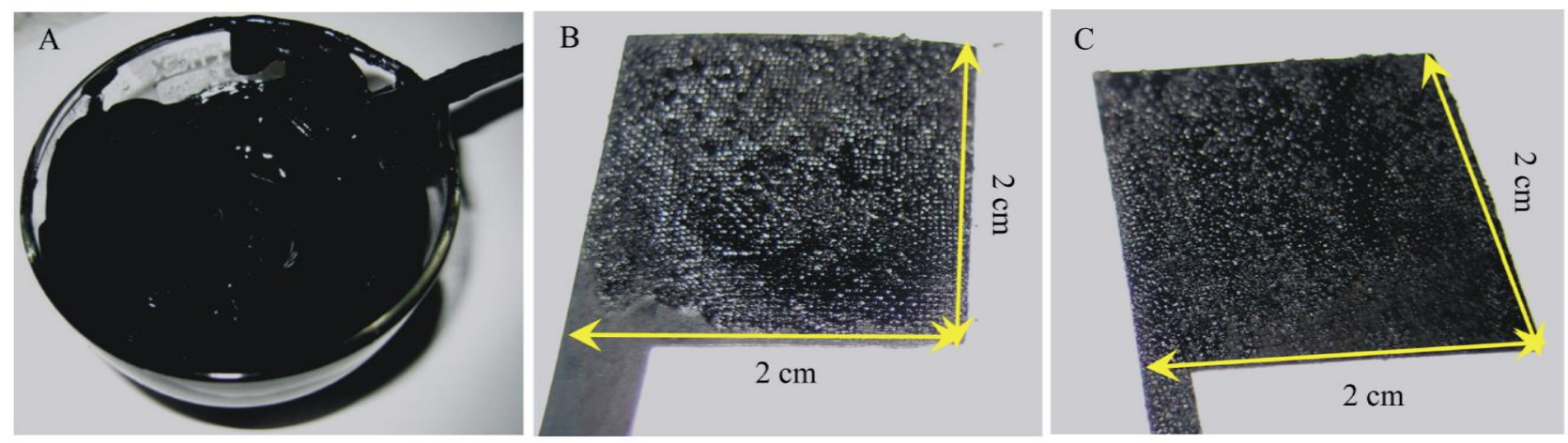

Fig. 8 Photographs of a typical ink of CNT-conducting polymer for screen printing (A), and the screen printed activated carbon (B) and CNT-PPy composite (C) on Ti plates [48].

It is acknowledged that the above discussion on preparation of redox materials is very selective. In the literature, many other studies and strategies are reported to understand and develop electrode materials. For example, the free standing buckypaper electrodes were utilised to improve the energy capacity [49], electrode strength [40] and scalable production of the electrode materials [44]. An interesting study shows that CNTs can be ruptured by voltammetric cycling the CNTs electrode 
beyond the electrolysis limit in acid solution, where the residual catalyst nanoparticles in the CNT were then exposed [49]. Composites of CNTs and pseudocapacitive conducting polymers and metal oxides for energy storage devices have also been discussed in the previous reviews [50,51].

\section{Conclusions}

In this review, we have introduced selected redox active materials, including inorganic compounds and conducting polymers, for uses as the electrode materials in supercapattery which represents a wide range of hybrid electrochemical energy storage devices. Because of the theoretical limit of specific capacitance of the carbon based EDLC, most reported devices with high energy capacity comprise at least one redox material electrode. The definition of supercapattery literally includes the components of most recently developed hybrid electrochemical energy storage devices (except for flow battery which is not discussed here). A supercapattery possesses the performance features of a capacitor and exhibits rectangular CVs and linear GCDs. The hybrid structure of supercapattery is different from EDLC and battery. The redox materials play an important role in the hybrid, providing the high energy capacity. The application of redox materials in supercapacitor or supercapattery does not change the intrinsic characteristics of redox materials which could offer either the capacitive (pseudocapacitive) or the non-capacitive (battery-like) Faradaic charge storage mechanism. Although the redox materials possess high energy capacity, not all of them can be fully utilised directly in practice because of their characteristic morphology and electronic conductivity. Combination of these redox materials with nanostructured EDLC materials, e.g. CNTs, can be achieved by either electrochemical co-deposition or chemical synthesis, leading to significantly improved charge storage performance. Meanwhile, a recent report on a supercapattery based on a Li metal negatrode and an activated carbon positrode is introduced here. The reported value of specific energy is very promising, up to $230 \mathrm{Wh} \mathrm{kg}^{-1}$ at the galvanostatic charge-discharge current density of $1 \mathrm{~mA} \mathrm{~cm}{ }^{-2}$. All these results promise a bright future for supercapattery containing redox materials, calling for more effort in research and technology development. 


\section{Acknowledgements}

This work received funding from Ningbo Municipal Government (3315 Plan and IAMET Special Fund, 2014A35001-1).

\section{Reference}

[1] A. Gabriel-Buenaventura, B. Azzopardi, Renewable \& Sustainable Energy Reviews, 41 (2015) 955-964.

[2] M.L. Zheng, C.J. Meinrenken, K.S. Lackner, Applied Energy, 126 (2014) 297-306.

[3] A.J. Stevenson, D.G. Gromadskyi, D. Hu, J. Chae, L. Guan, L. Yu, G.Z. Chen, Supercapatteries with Hybrids of Redox Active Polymers and Nanostructured Carbons, in: Nanocarbons for Advanced Energy Storage, Wiley-VCH Verlag GmbH \& Co. KGaA, 2015, pp. 179-210.

[4] C. Klumpner, G. Asher, G.Z. Chen, Selecting the Power Electronic Interface for a Supercapattery Based Energy Storage System, Ieee, New York, 2009.

[5] L. Yu, G.Z. Chen, Faraday Discussions, (2016) DOI: 10.1039/C5FD00232J.

[6] L. Guan, L. Yu, G.Z. Chen, Electrochimica Acta, (2016) DOI: 10.1016/j.electacta.2016.01.213.

[7] G.Z. Chen, ResearchGate, (2015) DOI: 10.13140/RG.2.1.4461.0642.

[8] S. Makino, Y. Shinohara, T. Ban, W. Shimizu, K. Takahashi, N. Imanishi, W. Sugimoto, Rsc Advances, 2 (2012) 12144-12147.

[9] B. Akinwolemiwa, C. Peng, G.Z. Chen, Journal of the Electrochemical Society, 162 (2015) A5054-A5059.

[10] P. Simon, Y. Gogotsi, Nature Materials, 7 (2008) 845-854.

[11] K.C. Ng, S.W. Zhang, C. Peng, G.Z. Chen, Journal of the Electrochemical Society, 156 (2009) A846-A853.

[12] M. Winter, R.J. Brodd, Chemical Reviews, 104 (2004) 4245-4270.

[13] R. Kotz, M. Carlen, Electrochimica Acta, 45 (2000) 2483-2498. 
[14] J. Chae, K.C. Ng, G.Z. Chen, Proceedings of the Institutiion of Mechanical Engineers, Part A:

Journal of Power and Energy, 224 (2010) 479-503.

[15] J. Chae, G.Z. Chen, Electrochimica Acta, 86 (2012) 248-254.

[16] A. Lewandowski, A. Olejniczak, M. Galinski, I. Stepniak, Jounal of Power Sources, 195 (2010) 5814-5819.

[17] X.H. Zhou, C. Peng, G.Z. Chen, AIChE Journal, 58 (2012) 974-983.

[18] C. Peng, S.W. Zhang, X.H. Zhou, G.Z. Chen, Energy \& Environmental Science, 3 (2010) 1499-1502.

[19] Z.-H Huang, Y. Song, X.-X. Xu, X.-X Liu, ACS Applied Materials \& Interfaces, 7 (2015) 25506-25513.

[20] S.W. Zhang, C. Peng, K.C. Ng, G.Z. Chen, Electrochimica Acta, 55 (2010) 7447-7453.

[21] F. Zhang, T.F. Zhang, X. Yang, L. Zhang, K. Leng, Y. Huang, Y.S. Chen, Energy \& Environmental Science, 6 (2013) 1623-1632.

[22] S.A. Klankowski, G.P. Pandey, G.A. Malek, J. Wu, R.A. Rojeski, J. Li, Electrochimica Acta, 178 (2015) 797-805.

[23] web link: https://en.wikipedia.org/wiki/Lithium-ion_battery\#cite_note-7

[24] J.P. Zheng, P.J. Cygan, T.R. Jow, Journal of the Electrochemical Society, 142 (1995) 26992703.

[25] J.P. Zheng, Electrochemical and Solid State Letters, 2 (1999) 359-361.

[26] S.C. Pang, M.A. Anderson, T.W. Chapman, Journal of the Electrochemical Society, 147 (2000) 444-450.

[27] M.Q. Wu, G.A. Snook, G.Z. Chen, D.J. Fray, Electrochemistry Communications, 6 (2004) 499-504.

[28] X. Jin, W. Zhou, S. Zhang, G.Z. Chen, Small, 3 (2007) 1513-1517.

[29] X.L. Wang, X.Y. Fan, G. Li, M. Li, X.C. Xiao, A.P. Yu, Z.W. Chen, Carbon, 93 (2015) 258265. 
[30] I. Ryu, G. Kim, D. Park, S. Yim, Journal of Power Sources, 297 (2015) 98-104.

[31] F. Li, G. Li, H. Chen, J.Q. Jia, F. Dong, Y.B. Hu, Z.G. Shang, Y.X. Zhang, Journal of Power Sources, 296 (2015) 86-91.

[32] G.Z. Chen, Progress in Natural Science-Materials International, 23 (2013) 245-255.

[33] M.S. Park, Y.G. Lim, J.W. Park, J.S. Kim, J.W. Lee, J.H. Kim, S.X. Dou, Y.J. Kim, Journal of Physical Chemistry C, 117 (2013) 11471-11478.

[34] V. Augustyn, J. Come, M.A. Lowe, J.W. Kim, P.L. Taberna, S.H. Tolbert, H.D. Abruna, P. Simon, B. Dunn, Nature Materials, 12 (2013) 518-522.

[35] J.C. Carlberg, O. Inganas, Journal of the Electrochemical Society, 144 (1997) L61-L64.

[36] G.Z. Chen, M.S.P. Shaffer, D. Coleby, G. Dixon, W.Z. Zhou, D.J. Fray, A.H. Windle, Advanced Materials, 12 (2000) 522-526.

[37] M. Hughes, G.Z. Chen, M.S.P. Shaffer, D.J. Fray, A.H. Windle, Chemistry of Materials, 14 (2002) 1610-1613.

[38] M. Hughes, M.S.P. Shaffer, A.C. Renouf, C. Singh, G.Z. Chen, J. Fray, A.H. Windle, Advanced Materials, 14 (2002) 382-385.

[39] G.A. Snook, G.Z. Chen, D.J. Fray, M. Hughes, M. Shaffer, Journal of Electroanalytical Chemistry, 568 (2004) 135-142.

[40] J.F. Che, P. Chen, M.B. Chan-Park, Journal of Materials Chemistry A, 1 (2013) 4057-4066.

[41] M.Q. Wu, G.A. Snook, V. Gupta, M. Shaffer, D.J. Fray, G.Z. Chen, Journal of Materials Chemistry, 15 (2005) 2297-2303.

[42] C. Peng, G.A. Snook, D.J. Fray, M.S.P. Shaffer, G.Z. Chen, Chemical Communications, (2006) $4629-4631$.

[43] C. Peng, J. Jin, G.Z. Chen, Electrochimica Acta, 53 (2007) 525-537.

[44] M.R. Arcila-Velez, R.K. Emmett, M. Karakaya, R. Podila, K.P. Diaz-Orellana, A.M. Rao, M.E. Roberts, Synthetic Metals, 215 (2016) 35-40.

[45] G.A. Snook, C. Peng, D.J. Fray, G.Z. Chen, Electrochemistry Communications, 9 (2007) 83-88. 
[46] G.A. Snook, G.Z. Chen, Journal of Electroanalytical Chemistry, 612 (2008) 140-146.

[47] D. Hu, C. Peng, G.Z. Chen, ACS Nano, 4 (2010) 4274-4282.

[48] X.H. Zhou, G.Z. Chen, Journal of Electrochemistry, 18 (2012) 548-565.

[49] R.K. Emmett, M. Karakaya, R. Podila, M.R. Arcila-Velez, J.Y. Zhu, A.M. Rao, M.E. Roberts, The Journal of Physcial Chemistry C, 118 (2014) 26498-26503.

[50] C. Peng, S.W. Zhang, D. Jewell, G.Z. Chen, Progress in Natural Science, 18 (2008) 777-788.

[51] V. Augustyn, P. Simon, B. Dunn, Energy \& Environmental Science, 7 (2014) 1597-1614. 